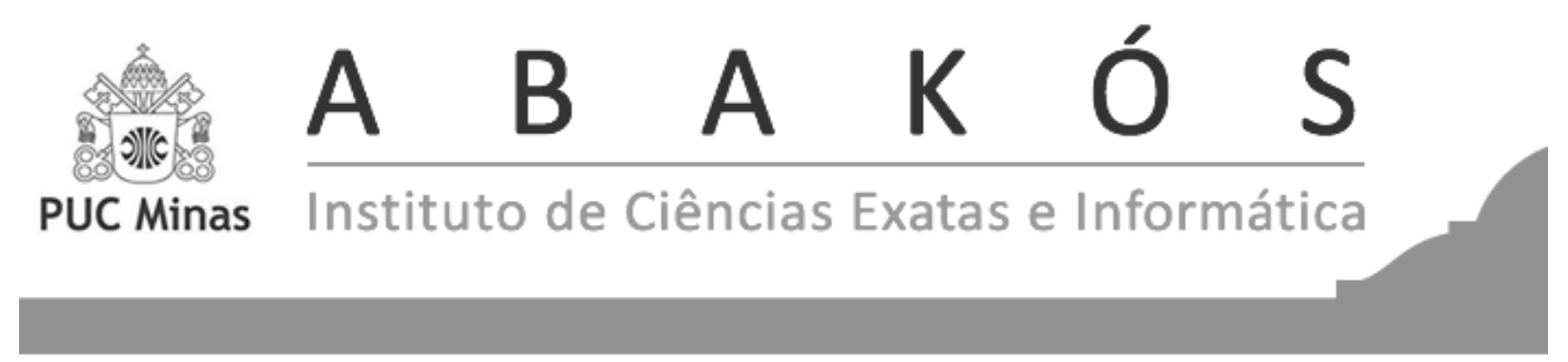

\title{
Tecnologias da Informação e Comunicação Aplicadas aos Processos de Ensino e de Aprendizagem: percepção de um grupo focal de professores de uma escola do Maranhão*
}

Information and Communication Technologies Applied to the Teaching and Learning Processes: teachers' perception of a focus group ina school of Maranhão

Vicente Henrique de Oliveira Filho ${ }^{1}$

Gilberto Tavares dos Santos ${ }^{2}$

Celina Aparecida Almeida Pereira $\mathrm{Abar}^{3}$

\begin{abstract}
Resumo
O presente artigo apresenta uma pesquisa sobre as implicações do uso das Tecnologias da Informação e Comunicação (TIC) nos processos de ensino e de aprendizagem na visão dos professores. Trata-se de uma pesquisa qualitativa, que utilizou a técnica dos grupos focais com uma pergunta geradora para coletar os dados necessários e realizar as análises subsequentes. Percebeu-se que há falta de preparo dos professores entrevistados para o uso das TIC em sua prática pedagógica, reduzindo-as apenas a um recurso adicional, pouco explorando as suas várias funcionalidades. É necessário, portanto, que a utilização dessas tecnologias pelos professores ultrapasse a dimensão utilitarista e seja incorporada como novas possibilidades educativas. Conclui-se que a subutilização das TIC pelos professores entrevistados é decorrente da falta de conhecimento e preparo para o uso dessas tecnologias como ferramenta didática. Essa limitação precisa ser superada por meio de uma adequada formação docente.
\end{abstract}

Palavras-chave: TIC. Ensino. Aprendizagem. Formação Docente.

\footnotetext{
*Submetido em 12/05/2016 - Aceito em 16/02/2017

${ }^{1}$ Licenciado em Matemática, Mestre em Educação e Ciências e Matemática da Pontifícia Universidade Católica do Rio Grande do Sul, (PUCRS). Doutorando em Educação Matemática da Pontifícia Universidade Católica de São Paulo. (PUCSP), Brasil - enriqueoliver2005@yahoo.com.br

${ }^{2}$ Doutor em Engelharia de Produção, Professor Adjunto da Escola de Administração da Universidade Federal do Rio Grande do Sul, (UFRGS), Brasil - gilberto.tavares@ufrgs.br

${ }^{3}$ Doutora em Lógica Matemática. Professora da Pontifícia Universidade Católica de São Paulo, atua no Programa de Estudos Pós-Graduados em Educação Matemática (PUCSP)., Brasil - abarcaap@ pucsp.br
} 


\begin{abstract}
This paper presents a research on the implications of the use of Information and Communication Technology (ICT) in teaching and learning processes from the teachers' point of view. This is a qualitative research, using the focus group technique, starting with a generating question to collect the necessary data and carry out further analysis. It was noticed that the interviewed teachers have demonstrated lack of preparation to use ICT in their teaching performance, reducing them to an additional resource, little exploring its many features. It is necessary, thus, that the use of ICT transcends the utilitarian dimension and isincorporated as new educational possibilities. We conclude that the interviewed teachers underuse ICT due to the lack of knowledge and preparation for the use of these technologies as a teaching tool. This restriction must be overcome by a suitable teacher training.
\end{abstract}

Keywords: ICT. Teaching. Learning. Teacher Training. 


\section{USO DAS TECNOLOGIAS DA INFORMAÇÃO E COMUNICAÇÃO E OS PROCES- SOS DE ENSINO E APRENDIZAGEM}

As Tecnologias da Informação e Comunicação (TIC) são um conjunto de recursos tecnológicos utilizados de forma conjunta para atender a uma necessidade de comunicação. $\mathrm{Na}$ prática, trata-se do desenvolvimento de software e hardware que visam fortalecer a comunicação por meios digitais e virtualmente. As TIC são utilizadas em vários campos de atuação, tais como: (i) o setor produtivo, em que os processos automatizados facilitam a realização e o monitoramento das suas diversas etapas, (ii) o setor de serviços, que busca estabelecer proximidade com clientes, e (ii) o setor educacional, para estimular o processo de ensino e aprendizagem, seja a distância ou presencial. As TIC, por meio de rede de computadores, uso de e-mail, videoconferências, realização de fóruns de discussão, agendamento de discussão em grupo, criação de ambientes virtuais e outras tantas ferramentas de suporte auxiliam a criar e manter o relacionamento entre as pessoas, oportunizando o intercâmbio de informações e experiências sobre os mais diversos temas (MORAN, 2007).

$\mathrm{Na}$ educação, as TIC, em especial a Internet, potencializam a criação de ambientes interativos de aprendizagem entre os sujeitos do conhecimento, dentro e fora da escola. O uso das TIC facilita o acesso à informação, que pode gerar a construção de novos conhecimentos, contribuir para a formação de novas atitudes e para a inserção na sociedade cada vez mais globalizada. Somos constantemente desafiados a ensinar e a aprender novos conteúdos em movimentos de atualização. Precisamos estar abertos a essa nova realidade que está diante de cada um de nós (VALENTE, 2005). Kenski (2013) acrescenta que "o tempo do conhecimento é múltiplo e atual. Informações são acessadas ao mesmo tempo, sem cronologia, sem sequência, sem hierarquia".

A escola precisa estar aberta a novas maneiras de aprender e ensinar e se configurar como um espaço onde todos possam ser aprendizes, onde ocorra a socialização de saberes e diferentes fazeres atrelados aos processos midiáticos de produzir e ampliar o conhecimento. Para isso, docente e discente precisam seguir juntos, sendo o professor o mediador do processo de aprendizagem (PRETI, 2007).

Nesse contexto, as TIC ocupam um papel central nas profundas mudanças ocorridas em todos os aspectos da vida social. E as redes sociais, mais especificamente, segundo Recuero (2009), "são construções plurais de um sujeito, representando múltiplas facetas de sua identidade". Para Silva (2014), precisamos pensar a interatividade nas redes sociais como uma nova modalidade comunicacional em emergência em um contexto complexo e de múltiplas interferências e de causalidades. O autor afirma que a interatividade não é apenas fruto de uma tecnicidade informática, mas uma nova reconfiguração das comunicações humanas em toda a sua amplitude. Bedin e Barwaldt (jul. 2014) agregam ser importante utilizar as redes de comunicação já que são ferramentas de domínio dos estudantes e têm a sua utilização facilitada, disponibilizando possibilidades diversas e inovadoras para o processo de ensino e aprendizagem. 
O uso das TIC nos processos de ensino e de aprendizagem, segundo Moran (2007), é fundamental para flexibilizar e mudar a apresentação desses processos. Porém, como explica Pescador e Flores (jul. 2013), o acesso à tecnologia deve garantir o desenvolvimento do pensamento crítico, reflexão e socialização e assim validar o processo de inclusão digital.

Castells (2003) considera que a Internet "é um meio de comunicação que permite intercâmbio de muitos com muitos, num momento escolhido, em escala global" e que permite a mediação com diferentes culturas. O autor ressalta que "a cultura é um conjunto de valores e crenças que formam o comportamento" (CASTELLS, 2003). O autor evidencia que o uso da Internet está relacionado à questão cultural, como uma forma de comunicação por meio de ícones e códigos de comunicação que expressam a maneira cultural de diversos povos. Entende-se, portanto, que professor e estudante, como sujeitos participantes desse processo mediático, podem interagir com outros conteúdos, com realidades diversas e com outras formas de ensinar e aprender. $\mathrm{O}$ acesso à Internet é o canal aberto à participação no mundo digital e em ambientes colaborativos de aprendizagem. (LOPES; ALVES, dez. 2011) acrescentam que os princípios da conectividade, hipertextualidade, emergência e convergência aplicados a experiências em sala de aula proporcionam ambientes de ensino e aprendizagem onde imersão, engajamento, interatividade e colaboração entre alunos e professores são verificados.

Isso nos leva a refletir que, se os docentes ainda não percebem as potencialidades do computador para ampliação do seu universo cultural, como, então, comunicarão ou mediarão conhecimentos com os estudantes por meio dessa tecnologia? Seria ingênuo pensarmos que integrarão o computador e a Internet à prática educativa sem compreender suas potencialidades e especificidades na sua prática pessoal enquanto profissionais.

Partindo desses pressupostos, foi delineada uma pesquisa com o objetivo de saber como os professores utilizam, em suas aulas, as tecnologias existentes na escola e como acontece esse processo? O objetivo da pesquisa foi identificar se a utilização desses recursos tecnológicos se restringia à utilização técnica dos mesmos, ou se, de fato, serviriam como ferramenta pedagógica cuja utilização apoiaria a aprendizagem dos alunos.

Desse modo, o artigo está organizado nas seguintes etapas: (i) apresentação introdutória do tema a ser desenvolvido, relativamente ao uso de TIC nos processos de ensino e aprendizagem (esta etapa), (ii) contribuição teórica no que diz respeito ao impacto das tecnologias na prática docente, (iii) detalhamento da pesquisa de campo realizada e os resultados obtidos, e (iv) considerações finais sobre o trabalho, relacionando resultados alcançados à visão teórica presente, limitações verificadas e as sugestões de trabalhos subsequentes.

\section{O IMPACTO DAS TECNOLOGIAS NA PRÁTICA DOCENTE}

Nos dias de hoje, a maioria dos estabelecimentos de ensino ainda mantém o modelo tradicional de ensino, baseado somente em aulas expositivas e o uso da tecnologia "giz" pelos professores, com alunos sendo meros ouvintes. No entanto, a prática docente deve ser orientada 
por uma nova lógica fundamentada na exploração de novos espaços e tempos de aprendizagem, não excludentes, que possibilitem a reflexão e estimulem relações entre áreas de conhecimento aparentemente distintas. Nessa abordagem, se alteram, principalmente, os procedimentos didáticos, pois é preciso que o professor faça a mediação entre o estudante e as TIC com vistas a fazer o discernimento entre as informações que circulam na web.

Para Valente (2005), a informação relaciona-se aos fatos e aos dados encontrados em meios impressos e digitais e àqueles intercambiados entre as pessoas. Já o conhecimento referese àquilo que as pessoas constroem como resultado do processamento, interpretação e compreensão da informação. O estudante deve processar a informação em interação com o mundo em que vive. Assim, a sua aprendizagem materializa-se em um ciclo contínuo de apropriação da informação de acordo com os conhecimentos já adquiridos. Por outro lado, o ensino deixa de ser a mera transmissão da informação, cabendo-lhe criar ambientes de aprendizagem para que o aluno interaja com diversas situações associadas ao seu cotidiano. Ou seja, o docente deve estar preparado para participar do processo de aprendizagem do aluno para que ele seja capaz de transformar as informações em conhecimento. Assim, a tecnologia tem papel muito relevante para dar suporte à atuação do professor.

Nesse contexto de reconhecimento da tecnologia, Kenski afirma que

as tecnologias digitais introduzem uma nova dinâmica na compreensão das relações com o tempo e o espaço. A velocidade das alterações, que ocorrem em todas as instâncias do conhecimento e que se apresentam com o permanente oferecimento de inovações, desequilibra a previsibilidade do tempo do relógio e da produção em série. O mundo se acelera, o avanço frenético das descobertas científicas impulsiona a produção e o consumo de novas formas de vida, permeadas pelas tecnologias. Novos avanços em pesquisas relativizam os conhecimentos anteriores. Tudo se torna descartável, possível de ser superado rapidamente. Prevalece a lógica do efêmero, do pontual (KENSKI, 2013).

Nessa perspectiva, a dinâmica da sala de aula em que alunos e professores encontramse fisicamente presentes, também se altera: o tempo e o espaço são os da experimentação e da ousadia em busca de caminhos e de alternativas possíveis, de diálogos e trocas sobre os conhecimentos em pauta, de retroalimentação permanente de tudo e de todos.

Freire (1993) deixa claro que professor e estudante são sujeitos de um processo, em que crescem juntos, porque ninguém educa ninguém, ninguém se educa sozinho. Os homens se educam entre si, mediatizados pelo mundo. Para Echeverría (2015), é necessário para o docente pensar no futuro e sobre o papel da escola na sociedade atual. E isso implica repercutir e repensar sobre o presente, para melhorar o futuro com o objetivo de explorar as inter-relações e as mudanças no estabelecimento de ensino ao longo do tempo.

Corroborando com essa ideia, Preti (2007) afirma que 'a mediação tecnológica não pode eliminar ou querer se colocar no lugar da mediação humana. A própria tecnologia precisa ser (re)humanizada, pois ela é uma extensão do homem, é um produto humano e que faz parte do processo de hominização". Moran et al. (2003) consideram que o recurso por si só não garante a inovação de um processo, mas depende sim de um projeto bem elaborado, alimentado pelos seus usuários. Reafirmando essa ideia, Imbernón (2009) salienta que a escola passa pelo 
processo de ação-reflexão-ação, básico para o desenvolvimento da ação docente reflexiva e para a evolução das ações pedagógicas necessárias e exigidas pelo paradigma dominante.

As TIC, enquanto ferramentas, não são um instrumento que ensina o estudante, mas com elas o estudante pode desenvolver determinada tarefa, seja na escola ou fora dela, interagindo na cultura midiática e buscando conhecimento pelas informações obtidas. As TIC permitem que sejam explorados aspectos pedagógicos que os alunos desenvolvem com material tradicional (PRETI, 2007). Para Kenski,

[...] essas novas maneiras de pensar e agir das novas gerações digitais influenciarão o futuro das escolas e da educação de modo geral. Será preciso, cada vez mais, ampliar ações e políticas efetivas, que propiciem a inclusão digital de todos os cidadãos. Ações que vão além do uso escolar de computadores e redes e se ampliem de forma intensiva para o acesso em espaços sociais diferenciados. É claro que, no entanto, é ainda a escola - em todos os seus níveis e formas - o espaço privilegiado e propício para desencadear a ação e a fluência digital (KENSKI, 2012).

Nesse aspecto, os discentes já pertencem a uma civilização que podemos chamar de icônica, enquanto os professores ainda pertencem a uma civilização pré-icônica. Esse fato não pode ser ignorado. Por essa razão, todo esforço deve ser despendido no sentido de uma preparação sólida do professor para lidar com a presença das tecnologias que exigem novas habilidades das pessoas. Caso contrário, "seria como se um analfabeto tivesse a pretensão de ensinar a alguém que já sabe ler o bom uso da língua” (SAMPAIO; LEITE, 1999).

O professor aprende no coletivo e constrói sua identidade profissional a partir das trocas experienciais mútuas entre seus pares. Faz-se necessária a reconstrução de seu processo de formação para atuar de maneira proficiente, utilizando as TIC como uma ferramenta para promover o ensino e a aprendizagem (FRANCO, 1997). Para o autor, o domínio das novas interfaces tecnológicas é fundamental para a sobrevivência do indivíduo na sociedade. Corroborando com esse pensamento, (FAVA, 2014) explicita que "a qualidade dos lações interpessoais de um nodo, e as informações que esses laços circulam, determinam a influência desse nodo. O padrão específico dos laços é crucial para entender como as redes, as conexões, os nodos (estudantes) funcionam e aprendem."

A maioria de nossas escolhas são referenciadas em preferências, sejam individuais ou coletivas, em que cada sujeito é movido pelo segmento de interesse e atua nesse ambiente interativo, onde não há linearidade. Com a imersão nas redes sociais, o aprendiz torna-se receptor e ao mesmo tempo produtor de diferentes conteúdos. Com o advento dessas redes sociais, a aprendizagem pode deixar de ser segmentada e estanque e passar a ser uma construção aberta e pontual, atrelada aos gostos e preferências do aprendiz. É o que se denomina de ciberespaço (SANTAELLA; LEMOS, 2010).

(LIZ; QUAREZEMIN, 2014) argumentam que o surgimento das TIC só favorece o enriquecimento da produção escrita pela criança, desde que orientada pelo professor, no sentido de que o computador seja utilizado para estimular diferentes habilidades de leitura e escrita. Para isso, o imprescindível é que os professores tenham familiaridade com o emprego das TIC, a fim 
de incorporá-las às suas práticas pedagógicas e à realidade vivencial dos alunos.

Para os autores, a função principal do professor é ser o mediador dos processos de ensino e de aprendizagem. A atividade cognoscitiva do aluno é a base do ensino e dá direção e perspectiva a todas as atividades organizadas pelo professor em situações didáticas específicas.

\section{PESQUISA DE CAMPO}

A escola onde o estudo foi realizado, localizada no estado do Maranhão, proporciona o Ensino Fundamental com 25 professores para aproximadamente 850 alunos. Os professores receberam, desde um ano antes da realização desta pesquisa, formação continuada a cada seis meses sobre tecnologia e o processo de ensino e aprendizagem. A escola conta com um laboratório de informática em que os computadores permitem acesso à Internet e ao software livre Linux Educacional. Nas salas de aula, os professores contam com o suporte de equipamentos multimídia e aparelhos de televisão para apresentar os conteúdos, em compartilhamento com outros professores, já que não há equipamentos suficientes para cada uma das salas de aulas da escola.

A pesquisa foi realizada com um grupo de dez professores (denominados de "A" a "J") com idades entre vinte e cinco a cinquenta anos; seis professores do gênero feminino e quatro do masculino. A escolha dos participantes buscou definir amostra representativa do universo de professores da escola nos quesitos idade e gênero. Todos os sujeitos possuem curso superior de licenciatura em variadas áreas. Desse universo, sete professores possuem especialização na área de educação e um deles fez mestrado em meio ambiente. Todos os professores participaram espontaneamente da pesquisa, que foi realizada no final do expediente, na própria escola.

O objetivo da pesquisa era saber como os professores utilizavm em suas aulas as tecnologias existentes na escola e como acontece esse processo. Buscou-se, também, identificar se a utilização desses recursos tecnológicos se restringia à utilização técnica dos mesmos, ou se de fato serviriam como ferramenta pedagógica cuja utilização apoiasse a aprendizagem dos alunos.

A técnica de coleta de dados utilizada foi o grupo focal. Essa estratégia de pesquisa possibilita uma maior escuta sobre um tópico de interesse, uma vez que os participantes do grupo conversam, debatem, trocam ideias entre si, e não com o pesquisador (EDMUNDS, 1999). O tema sugerido para debate com o grupo partiu da seguinte questão: Como você organiza seu trabalho pedagógico utilizando as TIC na sala de aula?

A análise das respostas constatou que os professores agregam as TIC ao planejamento das aulas sem entender as implicações e possibilidades de utilização das mesmas. Apesar disso, ao serem questionados se acreditavam ser positivo utilizá-las em sua prática pedagógica, todos (100\%) afirmaram que sim. Entretanto, suas respostas, ao mesmo tempo em que reafirmam a consciência da importância dessas tecnologias nos dias atuais, revelam uma visão superficial das possibilidades pedagógicas da sua utilização, percebendo-as apenas como um recurso didático 
adicional. É possível verificar essa constatação nas seguintes falas expressas pelos professores: "De vez em quando, gosto de variar no meu trabalho, proporcionar algo diferente para os alunos e então, uma vez por semestre, proporciono uma sessão de cinema. Os alunos adoram" (Prof. "A").

As afirmativas dos professores mostram que as TIC são utilizadas como recursos auxiliares de um ensino preocupado em repertoriar os discentes com as ferramentas utilizadas sem importarem-se com a reflexão decorrente do uso das TIC. Destacaram-se os seguintes comentários: "Não gosto de ficar presa apenas aos livros didáticos, acho importante ampliar conhecimentos através de outras fontes e, por isso, solicito constantemente pesquisas aos alunos, com isso eles utilizam a internet". (Prof. "B"). Enquanto que o (Prof. "C") afirma que "Utilizo alguns recursos tecnológicos para tornar minhas aulas mais dinâmicas e criativaspara motivar a participação dos alunos". Ou seja, há preocupação maior com a apresentação e aplicação das TIC do que com os resultados obtidos dessa utilização. Nenhum dos professores disse empregar qualquer método de acompanhamento das ferramentas quanto à eficácia pedagógica para a construção do conhecimento discente. Nesse sentido, é importante integrar as potencialidades das TIC nas atividades pedagógicas, de modo a favorecer a representação textual e hipertextual do pensamento do aluno, a seleção, a articulação e a troca de informações, bem como o registro sistemático das ações realizadas e respectivas produções, para que se possa recuperá-las, refletir sobre elas, efetuar as mudanças que se fizerem necessárias, estabelecer novas articulações entre informações e conhecimentos para desenvolver a espiral da aprendizagem.

A análise dos dados evidenciou que os professores não consideraram a pesquisa como conteúdo de ensino. De acordo com os Professores "D" e "H", eles estabelecem a busca de tópicos extraclasse (no laboratório de informática da escola) como atividade complementar à jornada de tempo estabelecida para as aulas presenciais. Isso é, a atividade conta mais pelo tempo despendido na sua realização do que pelo conhecimento a ser oportunizado, já que esse tipo de exercício não recebe acompanhamento quanto à sua execução, salvo a definição de datas para entregas e avaliação geral dos textos entregues. Os professores escolhem um tema e delegam sob a responsabilidade dos alunos a seleção e a organização das informações coletadas. Essa atividade não passa de uma cópia dos livros e de artigos da Internet. Os alunos não são instrumentalizados para a pesquisa, e não há reflexão sobre a qualidade dos conteúdos levantados. Nesse processo, os alunos são reprodutores de um discurso e não autores de análise textual própria.

Buscando aprofundar a compreensão acerca da utilização das TIC, foi solicitado aos professores que sinalizassem em suas respostas os recursos que mais utilizam na prática pedagógica. Ficou evidente a seguinte ordem de frequência de utilização: 1. Consulta a jornais e revistas digitais; 2. Consulta a livros digitais; 3.Uso de Televisão; 4. Envio de mensagens por correio eletrônico; 5. Acesso à Internet para realizar qualquer tipo de busca; 6 . Apresentação de filmes em Dvd; e 7. Consulta a blogs.

Quanto às dificuldades que os professores encontram na utilização pedagógica das TIC, foram enumeradas as seguintes: (i) a escola não dispõe de recursos ou os têm em pouca quan- 
tidade para atender à demanda; (ii) dificuldades de operacionalização dos equipamentos; (iii) falta de preparo do docente para lidar com as ferramentas; (iv) ausência de um responsável pelo suporte técnico; (v) falta de espaço adequado para utilização das tecnologias disponíveis; e (vi) falta de manutenção dos aparelhos. As limitações apontadas indicam a necessidade de aprimorar políticas públicas de inclusão digital para os professores, pois a não utilização das tecnologias na prática docente resulta da falta de conhecimento sobre as mesmas, e também da resistência ao novo.

Durante a discussão dos professores sobre as dificuldades que encontravam na utilização das TIC na prática pedagógica, fez-se necessário questioná-los sobre a utilização das mesmas na sua auto-formação, em atividades de estudo e pesquisa. As falas a seguir nos remetem a esse questionamento: "Para ampliar meus conhecimentos e melhorar a minha prática, sempre leio livros da área educacional" (Prof. "I"), e "Confesso que há muito tempo não leio livros e nem participo de capacitações. O tempo não deixa. Afinal são três turnos de trabalho" (Prof. "D”). Observa-se que a maioria dos professores consultados não busca conhecimento acerca das TIC e seus usos na prática. Por consequência, o rol de funcionalidades das TIC é desconhecido e a sua aplicação limitada.

Além disso, constata-se que o texto escrito é a principal fonte de informação e mediação utilizada pelos professores em seu processo de formação e informação. A fala a seguir caracteriza essa situação: "Sempre busco descobrir e adquirir os livros lançados pela editoras, especialmente aqueles que apresentam exercícios para praticar em sala de aula" (Prof. "E") e "Sempre estou à procura de novos conhecimentos. Procuro sempre que posso comprar livros na área em que atuo" (Prof. "G”).

Fica caracterizada a falta de preparo dos professores para o uso do computador em sua prática pedagógica, limitando-se ao uso do recurso didático sem objetivos previamente definidos, a despeito de o planejamento ter sido realizado. É necessário que a utilização dessa ferramenta pelo professor ultrapasse a dimensão utilitarista e seja incorporada a novas possibilidades educativas. Um exemplo de fala que registra essa situação: "Quando tenho um tempinho dou uma chegada na Internet, nos sites de busca e, é claro, no correio eletrônico também” (Prof. "F").

Para melhorar essa situação, deve-se considerar que os programas de formação de professores podem ser canais eficazes para promover a habilidade do professor quanto ao reconhecimento e uso das TIC, na medida em que se constitui em espaço específico para a reflexão sobre a relação tecnologia e educação e suas possibilidades pedagógicas.

Por fim, isto nos leva a refletir que, se esses docentes ainda não percebem as potencialidades das TIC para ampliação do seu universo cultural; como, então, comunicarão ou mediarão informações e conhecimentos com seus alunos por meio das TIC? É ingênuo pensar que os professores integrarão as TIC à sua prática pedagógica sem compreenderem suas potencialidades e especificidades para uso no seu cotidiano profissional. 


\section{CONSIDERAÇÕES FINAIS}

A informação tem grande poder de difusão, pode ser compartilhada, sem perda de seu controle. A informática pode nos auxiliar a criar uma sociedade em que prevaleçam a liberdade, a responsabilidade e a participação, baseadas em acesso generalizado às informações, expandindo o espaço de comunicação e ampliando fronteiras. O computador, além de ter condições de ser aliado nos processos de ensino e aprendizagem, traz para os estabelecimentos de ensino muitas vantagens em processar informações. A tecnologia modifica a expressão criativa do homem, alterando sua forma de construir conhecimento. A Internet, quando empregada de forma consciente e responsável pela escola, pode tornar o ensino mais compartilhado, significativo e aberto, modificando o modo de ensinar e aprender.

A mudança de paradigma é fundamental para que ocorram as transformações exigidas pela sociedade; portanto, o uso pedagógico das TIC pode contribuir para tais transformações. As características inerentes aos multimeios favorecem a realização de trabalhos reflexivos, criativos e investigativos, sobretudo no âmbito escolar.

Apesar de as reflexões obtidas neste estudo apontarem para a iminência de uma nova postura que encare as potencialidades e limitações do computador nos processos de ensino e de aprendizagem, o trabalho de campo realizado com os professores demonstrou o quanto ainda se está distante desse ideal, pelo menos no que diz respeito ao universo do estabelecimento de ensino envolvido neste trabalho.

Os professores entrevistados mostraram entendimento superficial acerca das possibilidades de utilização das TIC e das consequências desse uso. Percebe-se o incentivo ao discente pela busca de informação, porém não se mostra preocupação de como o conhecimento discente é elaborado a partir das informações coletadas, especialmente na Internet. Ou seja, a preocupação é maior com a aplicação da ferramenta do que com aquilo que se pode extrair da sua utilização, quais sejam as discussões e reflexões subsequentes que colaborarão para a melhor compreensão dos temas delineados. Em oposição a esse comportamento, Valente (2005) argumenta que o professor deve estar preparado para participar do processo de aprendizagem do aluno, a fim de que ele consiga converter as informações em conhecimento, relacionando-as à sua vida. No sentido de reafirmar o papel da tecnologia no processo de ensino e aprendizagem, Kenski (2012) afirma que as gerações digitais influenciarão o futuro da educação, fazendo com que sejam revistas e expandidas ações hoje existentes que propiciem a inclusão digital para os sujeitos do processo de ensino e aprendizagem. Franco (1997) é mais incisivo nessa questão, ao dizer que o domínio da tecnologia é fundamental para a sobrevivência dos indivíduos na sociedade contemporânea.

Para superar essa barreira quanto ao tratamento secundário da tecnologia no processo de educação, é preciso direcionar a formação docente para o acesso e a prática das suas potencialidades, aplicações e limitações. O professor é o condutor do processo de ensino e aprendizagem, por isso, deve estar associado à realidade dos alunos. É preciso que o docente tenha ideia clara de que ele é o colaborador para o processo de construção do conhecimento do aluno e, por 
isso, deve se manter atualizado quanto à realidade tecnológica existente e à realidade vivencial dos alunos. Liz e Quarezemin (2014) consideram ser fundamental que o professor tenha proximidade com o uso das TIC para que possa incorporá-las às suas práticas pedagógicas e em conexão com o cotidiano dos alunos. Moran (2007) acrescenta ser necessário que a escola disponibilize ensino direcionado à aprendizagem viva e criativa, com professores menos falantes e mais voltados para atividades de pesquisa e experimentação. Nesse aspecto, a escola objeto de estudo tem proporcionado a qualificação para o professor em período recente. É de se esperar que o docente atenda a esse propósito em períodos vindouros, a serem avaliados.

Com relação às limitações deste trabalho, considere-se o fato de que o levantamento realizado não tem representatividade estatística, de modo que os resultados obtidos não podem ser inferidos como ocorrendo com outros professores na mesma ou em diferentes escolas. Todavia, a característica do trabalho é eminentemente qualitativa, no sentido de sondar percepções, conhecimentos, atitudes e sentimentos sobre um tópico em particular; no caso, avaliar a percepção de um grupo de professores sobre conhecimento e o uso das TIC no processo de ensino e aprendizagem de que participam profissionalmente.

Para trabalhos futuros, sugere-se, como sequenciamento da pesquisa ora realizada, criar e aplicar pesquisa quantitativa que possa avaliar de forma sistemática e periódica a evolução no uso das TIC no processo de ensino e aprendizagem da escola objeto de estudo, assim como levantar as necessidades surgidas no decorrer do tempo. 


\section{REFERÊNCIAS}

BEDIN, E.; BARWALDT, R. Tecnologia da informação e comunicação no contexto escolar: interações à luz da sustentabilidade ambiental no viés das redes sociais. In: RENOTE (Revista Eletrônica de Tecnologia em Educação). Porto Alegre, jul. 2014. v. 12, n. 1. Disponível em: <http://seer.ufrgs.br/index.php/renote/article/view/49842/31198> Acesso em: 03 nov. 2014.

CASTELLS, M. A galáxia da internet: reflexões sobre a internet, os negócios e a sociedade. Rio de Janeiro: Jorge Zahar, 2003.

ECHEVERRÍA, J. A escola continua e o trabalho no espaço-tempo eletrônico. In: IMBERNÒN, Francisco; JARAUTA, Beatriz. Pensando no futuro da educação: uma nova escola para o século XXII. Porto Alegre: Penso, 2015.

EDMUNDS, H. The Focus Group Research Handbook. 1. ed. Chicago: NTC Business Booksm, 1999.

FAVA, R. Educação 3.0. 1. ed. São Paulo: Saraiva, 2014.

FRANCO, M. A. Internet: reflexões filosóficas de um informata. Transinformação, Campinas, v. 9, n. 2, 1997.

FREIRE, P. Pedagogia do oprimido. 21. ed. Rio de Janeiro: Paz e Terra, 1993.

IMBERNÓN, F. Formação permanente do professorado: novas tendências. São Paulo: Cortez, 2009.

KENSKI, V. M. Educação e Tecnologias: o novo ritmo da informação. Campinas, SP: Papirus, 2012.

KENSKI, V. M. Tecnologias e tempo docente. Campinas, SP: Papirus, 2013.

LIZ, L. L.; QUAREZEMIN, S. Formação de professores dos anos iniciais da educação básica na modalidade ead: ensino de língua materna e a influência das tecnologias da informação e comunicação. Educ. rev., n. spe 4, p. 173-190, 2014.

LOPES, T. R. C; ALVES, I. M. R. Novos meios, novas práticas de ensino-aprendizagem: proposta de produção colaborativa de um twiconto. In: RENOTE (Revista Eletrônica de Tecnologia em Educação). Porto Alegre, dez. 2011. v. 9, n. 2. Disponível em: <http://seer.ufrgs.br/index.php/renote/article/view/25161/14652> Acesso em: 04 maio 2014.

MORAN, J. M. A educação que desejamos: novos desafios e como chegar lá. Campinas, SP: Papirus, 2007.

MORAN, J. M.; BEHRENS, A. M.; MASETTO, M. T. Novas tecnologias e mediação pedagógica. Campinas, SP: Papirus, 2003.

PESCADOR, C. M.; FLORES, J. B. O Laptop Educacional na Escola: uma reflexão sobre inclusão digital. In: RENOTE (Revista Eletrônica de Tecnologia em Educação). Porto Alegre, jul. 2013. v. 11, n. 1. Disponível em: $<$ http://seer.ufrgs.br/index.php/renote/article/view/41690/26449> Acesso em: 04 maio 2014.

PRETI, O. A Formação do professor na modalidade a distância: (DEZ) construindo metanarrativas e metáforas. Revista Brasileira de Estudos Pedagógicos, v. 82, 2007. 
RECUERO, R. Redes sociais na Internet. Porto Alegre: Sulina, 2009.

SAMPAIO, M. N.; LEITE, L. Alfabetização tecnológica do professor. 4. ed. Petrópolis, RJ: Vozes, 1999.

SANTAELLA, L.; LEMOS, R. Redes sociais digitais: cognitiva do Twitter. São Paulo: Paulus, 2010.

SILVA, M. Sala de aula interativa: educação, comunicação, mídia clássica, Internet, tecnologias digitais, arte, mercado, sociedade, cidadania. 7. ed. São Paulo: Edições Loyola, 2014.

VALENTE, A. J. Pesquisa, comunicação e aprendizagem com o computador: o papel do computador no processo ensino-aprendizagem. In: ALMEIDA, M. E.; MORAN, J. M. Integração das tecnologias na educação. Brasilía: MEC/SEED, 2005. p. 22-31. 